\title{
INNOVATIVE LEARNING HUB'S ROLE IN LEARNING SPACE DESIGN
}

\author{
Aiman Khamitova \\ Nazarbayev University, Astana, Kabanbay str., 53, C2, 4052, Kazakhstan
}

\begin{abstract}
Author shares the Nazarbayev University (Astana) experience in transforming learning spaces into technology enhanced learning studios from the scratch. The process has not yet been finished, however, initial steps have been done. In particular, the Innovative learning hub was created and one of its tasks is to redesign one classroom in each block/School so that more engaging learning and different pedagogy approaches could take place.
\end{abstract}

\section{KEYWORDS}

Innovative Learning Hub, Learning Space Design

\section{INTRODUCTION}

The use of blended learning in higher education is considered to be one of the greatest trends in education, however, its implementation requires the core technological infrastructure, as space design. Mobile and personal technology is transforming the way learning spaces are used and configured. It allows learning to occur almost anywhere. One of blended learning efficiency factors is space that should be envisioned as a change agent in this transformational process. And this concept is vital for the Nazarbayev University, Kazakhstan's young institution, in becoming a flagman in the whole Central Asian region. NU could integrate the traditional with the innovative, using technologies, pedagogy and space, and support student and faculty research, teaching and learning which will serve a good example to follow by other institutions in the country.

\section{BODY OF PAPER}

The nowadays competencies like creativity, critical thinking, collaboration, digital literacy and citizenship are prerequisites for one to live, work and learn in a knowledge-based society with innovation at the core of it. this innovation is facilitated thanks to the technology created and distributed, while through technology new pedagogies are being developed, like blended learning.

The Innovative Learning Hub (Hub) was created at the Office of the Provost of Nazarbayev University (NU) in 2018 as a centrally located space that would serve as a "test bed" for multidisciplinary, blended learning transformation projects involving technology in teaching and learning, showcasing emerging applications and technologies promoting the innovative culture among faculty and staff as one of the main missions of the Hub is to provide ongoing faculty development of their teaching practices and course design.

In October 2018 at the meeting of the Academic Council the Provost tasked the Hub to start to redesign the classrooms. The Hub's staff started faculty focus groups, comprised of volunteers among the faculty, and it had been stressed that the redesign should provide:

- collaboration capacity so that all types of learning interactions can occur in the classrooms,

- mobility so that environments can adapt to new ideas and technologies, and

- innovative flexibility to give students the lifelong learning skills that they need to be effective in the workforce. 
Currently, the typical classroom at our University looks like a teacher area in the front with a whiteboard, a projector, a computer, a desk and a chair, an empty floor space and then students' seats with tiered floor.

According to the report by European Schoolnet and Microsoft, "Transforming learning spaces in schools: From vision to impact", dated by May 2018, in many countries the importance of developing more flexible learning spaces is already a part of the national strategy for innovation in schools. It is acknowledged that innovative use of tech and flexible learning spaces go hand in hand. Given that learning spaces have been identified as a developing trend in education, it is likely that the situation will continue to evolve rapidly and that adapting learning spaces will become an increasingly important issue for policymakers and school leaders in more countries (European Schoolnet, Microsoft, 2018).

Our hub is aimed at provision of space for technology rich experimentation, collaborative work areas, support for communities of practice on distance education, workshops and one-to-one tutoring for software and hardware innovations in new media technologies, educational presentations on emerging tech and practices. Our Innovative learning lead is conducting workshops for faculty on how to use IT to enhance the classroom experience in a "sandbox" environment. We also invite trainees not only among the Faculty of our University but also from abroad to share their experience. In April-May this year the Hub will purchase 1 iMac, 2 Macbook Air, 10 iPads for the e-textbooks creation, as well as a 360 camera and drone with the necessary software to enable tech projects and start producing multimedia digital resources for some of the disciplines to be transformed onto blended/flipped ones.

Many projects are launched with a "let's first build it and then everyone will adjust their practices" philosophy. But we want that here at NU we first decide what sort of teaching and learning activities will take place and then design the space. Therefore, Faculty were consulted broadly on the vision of the classroom via focus groups held for each classroom that needs to be redesigned. Currently, there are four classrooms that were selected to be the first ones to be redesigned. The main features that are fair to all the rooms are the following: teacher centered stand, more tech solution needed (not one monitor, but two and more to engage all the students), no tiered floor at all. Besides, faculty prefers small group interactions, face-to-face contact is critical to the culture of teaching and learning.

Thanks to our strategic partner in learning spaces design, University administration started to realize that when designing learning spaces it is vital to take into account learner expectations, the principles and activities that facilitate learning, and the role of technology. The following factors, if in place, will make our project successful:

collaborative design (produce collaboration among IT, Library, Offices of the President and Provost, as well as hardware, software and furniture companies);

technology and instructional support (our mission is to enhance teaching and learning through the thoughtful integration of innovative instructional technologies. Our recently hired Graphic instructional designer is available to work with faculty. Besides, we plan to hire interns who will get trained in building online course content and components, as well as e-textbooks);

trainings for faculty (we have innovative fellows who voluntarily contribute in promoting the innovation culture among the faculty (for example, one teaching fellow conducts trainings on Moodle). When the equipment that had been ordered for our Hub's room arrives, faculty will be able to consult our staff or student interns to decide for example what technologies might better engage learners);

Hub visitors may participate in a vendor-led product showcase or join a hands-on workshop on topics like "Blended course design" or "Copyright video features".

Student experience is an important starting point to the design process. It is well known that among the most successful institutions will be those that find ways to infuse student ideas into the design process. As collaboration is becoming more important soft skill that is natural for today's students modern learning space design seeks to provide freedom of access and interaction with peers. The percentage of students that come to our University from rural areas is not high, but still more collaborative space would provide them with equal opportunities and not hide - due to some societal features - behind more active (usually, urban) students.

An ideal classroom, according to our faculty and students, has flexible furniture arrangements, decenters the room from teacher to student activity, stresses collaboration and is tech integrated. In the long term we would like the design process enable the creation of permanently unfinished spaces that would be suitable for any type of adjustments due to the new technologies and pedagogical approaches. 


\section{CONCLUSION}

Major learning space design projects and their associated technology design efforts can effect significant transformations on a campus. Although the big transformational project is going on currently at NU, any changes are skeptically received from the administration and faculty side. For example, in terms of Rogers' Five Categories of Innovation Adopters, NU can be referred as to Early majority category when the adopters are fairly comfortable with technology but they only adopt a new innovation when they have compelling evidence of its value and solid recommendations from other adopters.

Overall, the main message to be delivered to the leadership on learning space design is that interior architecture and environments should be reconfigurable to accommodate multiple uses in a fixed space. Beyond seating, desk height, and equipment placement, the planners should consider appropriate lighting as well as climate and sound control. Speaking about the Astana climate, it is especially vital to install special systems that would not collapse when the temperature outside in summer may be 35C, while in winter $-40 \mathrm{C}$.

The way the learning spaces are used and configured is transformed by mobile and personal technology. It allows learning - including research, collaboration, creating, writing, production, and presentation - to occur almost anywhere (D.Pierce, 2015). And as nowadays students are mobile digital citizens, every institution that has a plan to grow needs to be ready to service them as best as possible.

\section{REFERENCES}

Dennis Pierce, 2015. 3 Ways Mobile Technology Is Transforming Learning Spaces. THE Journal, https://thejournal.com/articles/2015/08/25/3-ways-mobile-technology-is-transforming-learning-spaces.aspx.

Diana G. Oblinger et al, 2006. Learning spaces. Chapter 31. The Digital Union. EDUCAUSE, USA.

European Schoolnet, Microsoft, May 2018. Transforming learning spaces in schools: From vision to impact. https://onedrive.live.com/redir?resid=BDAA51D91DE98932\%21195\&authkey=\%21AFIYk_LSRM5Lq9k\&page=Vi ew\&wd=target\%28Overview.one\%7Cdea89a8c-93ee-42d9-af5d-81e84b632b1f\%2FOverview\%7C2d7ad4e7-e7fa4df5-9237-ce2581637d00\%2F\%29

Simon Kang'ethe Ngigi (Catholic University of Eastern Africa, Kenya) and Elizabeth A. Obura (Catholic University of Eastern Africa, Kenya), 2019. Blended learning in Higher Education: Challenges and opportunities. Research Handbook. 